\title{
Evaluation and redesign of manual material handling in a vaccine production centre's warehouse
}

\author{
Yaniel Torres $^{\mathrm{a},{ }^{*}}$ and Silvio Viña ${ }^{\mathrm{b}}$ \\ ${ }^{a}$ ErgoCuba research team, Ronda \# 5 Apto 8, Plaza de la Revolución, La Habana, Cuba, CP: 10300 \\ ${ }^{b}$ Department of Industrial Engineering, "José Antonio Echeverría" Institute of Technology, Calle 114, S/N, Ma- \\ rianao, La Habana, Cuba, CP: 19390
}

\begin{abstract}
This study was conducted in a warehouse at a vaccine production centre where improvement to existing storage and working conditions were sought through the construction of a new refrigerated store section $\left(2-8 \mathrm{C}^{\circ}\right)$. Warehousing tasks were videotaped and ergonomics analysis tools were used to assess the risk of developing MSDs. Specifically, these tools were the Rapid Entire Body Assessment (REBA) and the NIOSH equation. The current plant layout was sketched and analyzed to find possible targets for improvement trough the application of general work space design and ergonomics principles. Seven of the eight postures evaluated with REBA had a total score between 8 and 10, meaning a high risk, and only one was at a medium risk level. Nine of the eleven manual material handling tasks analyzed with the NIOSH equation had a Lifting Index between 1.14 and 1.80 and two had a recommended weight limit of $0 \mathrm{~kg}$, indicating a need for job redesign. Solutions included the redesign of shelves, the design of a two-step stair and a trolley with adjustable height; also, changes in work methods were proposed by introducing a two-workers lifting strategy and job rotation, and, finally, a restructuring of plant layout was completed.
\end{abstract}

Keywords: ergonomic intervention, lifting strategies, plant layout, NIOSH equation, REBA

\section{Introduction}

It is now generally acknowledged among Industrially Advanced Countries that Musculoskeletal disorders (MSDs) affect employees in most industries and occupations, and these injuries impose heavy costs on employers and society. In many manufacturing industries it is common that manual materials handling $(\mathrm{MMH})$ tasks are required, and these tasks are thought to contribute to some of the more costly occupational injuries, such as low back pain [4]. Although automation and other technologies have reduced the need for manual materials handling $(\mathrm{MMH})$ in some situations, there is still a need for these kinds of tasks. This need is more apparent in industrially developing countries due to the low level of automation and poor work organization.

Musculoskeletal disorders (MSDs) represent the second highest rate of total permanent disability in the Cuban work force, with an incidence rate of 180 cases for every 10000 workers; this rate is exceeded only by vascular-brain diseases and represents only the tip of the iceberg [9]. It is well known that MSDs are associated with jobs and tasks involving repetitive movements and exertion, including such specific risk factors as use of force, awkward posture and lack of recovery periods [3].

Improvement of working conditions is still the best means of prevention, and the key to improving these conditions is though Ergonomics. In 2007, Cuban Standards (NC) 3000, 3001 and 3002 entitled "Integrated Human Capital Management System" were issued. These standards proposed the necessity of ergonomic evaluations of the workplace. Generally, Cuban standards are not mandatory, but in this case the Cuban legislation made the NC-3000 mandatory. One of the main challenges that Cuban specialists in ergonomics face today is to conduct systematic ergo-

\footnotetext{
*Corresponding author. E-mail: yanieltm@yahoo.es
} 
nomic evaluations in enterprises and, consequently, set basic standards and regulations regarding this facet.

The use of ergonomics is consistent with the proactive approach, and the intervention presented in this paper is an example of this approach to enhancing workers' health. This study was conducted in a warehouse at a vaccine production centre where improvement to existing storage and working conditions were sought through the construction of a new refrigerated store section $\left(2-8 \mathrm{C}^{\circ}\right)$. The aim was to plan a new storage section, taking into consideration ergonomics principles to reduce the risk of suffering MSDs and attempting to optimize plant layout.

\section{Practice innovation}

Warehousing tasks were videotaped and ergonomics analysis tools were used to assess the risk of developing MSDs. Specifically, these tools were the Rapid Entire Body Assessment (REBA) and the NIOSH equation. A musculoskeletal symptoms questionnaire was distributed to the nine workers concerned with warehousing activities. The current plant layout was sketched and analyzed to find possible targets for improvement trough the application of general principles for designing work spaces and ergonomics view points. This approach seems to offer a broader base of information than those frequently used during ergonomics interventions in our context [8-10].
The requisites considered for design of the workplaces were: to decrease worker's physical effort, and to satisfy a minimum of $90 \%$ of the male and female population and to reduce the score obtained by REBA and by NIOSH equation. Anthropometric data on Cuban population was used in the study to determine optimal workplace dimensions. They were taken from "Medidas antropométricas de población laboral de 18 a 50 años" measured by Martínez, Moreno and Manero [1].

Solutions included the redesign of shelves, the design of a two-step stair and a trolley with adjustable height; also, changes in work methods were proposed by introducing a two-workers lifting strategy and job rotation, and, finally, a restructuring of plant layout was completed.

\subsection{Warehousing tasks}

Vaccines are stored in isothermal boxes. Most of the time vaccines are placed in group of 10 packs weighting $10 \mathrm{Kg}$ (Figure 1); these packages are introduced in isothermal boxes during the final packing phase. Critical postures associated with 8 tasks were evaluated with REBA and three groups of manual material handling tasks with the NIOSH equation, totaling eleven tasks for assessment. Evaluated tasks included: lifting 10 vaccines packs weighting $10 \mathrm{Kg}$ from trolley to shelves (4 subtasks), lowering 10 vaccine packs weighting $10 \mathrm{Kg}$ from shelves to isothermal boxes for final packaging (4 subtasks) and lifting isothermal boxes weighting $24 \mathrm{~kg}$ from pallets to

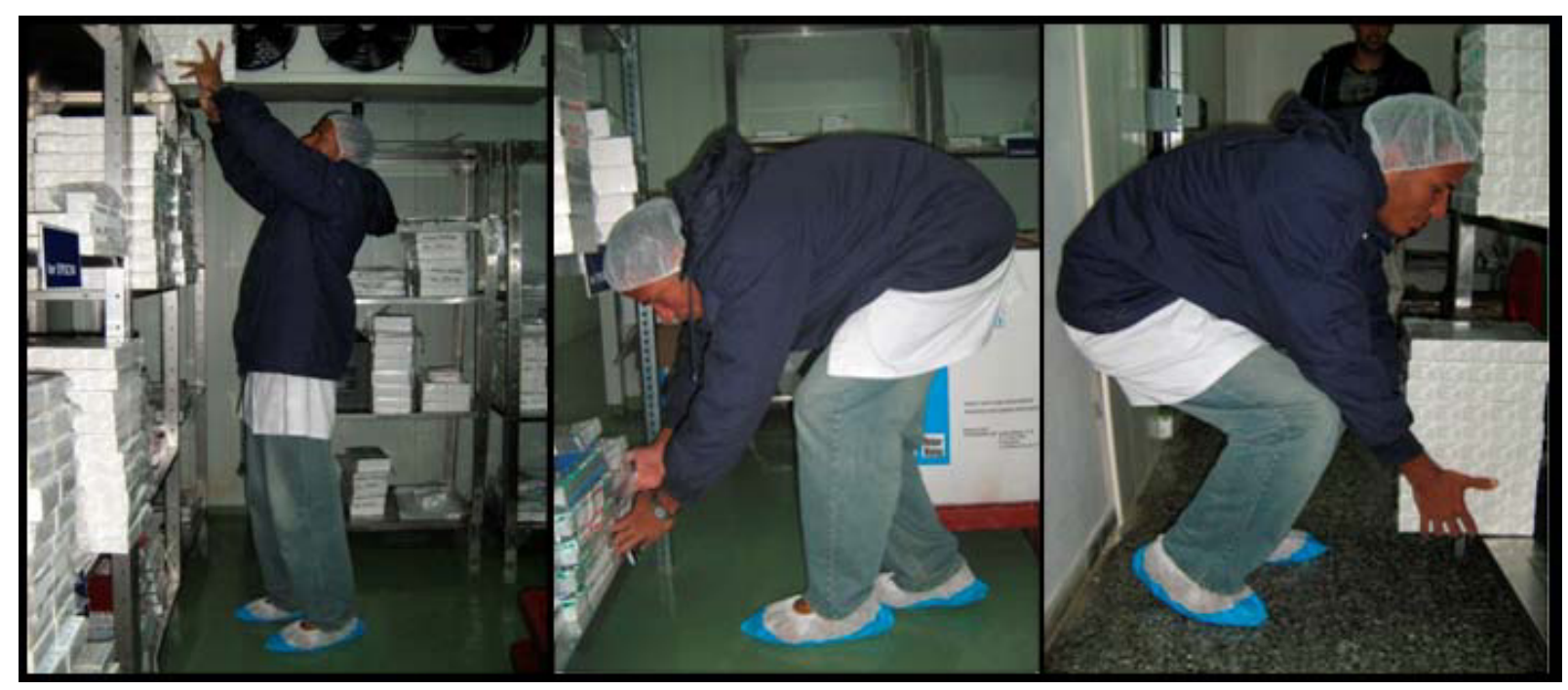

Fig. 1. Set of working posture during interaction with shelves. 


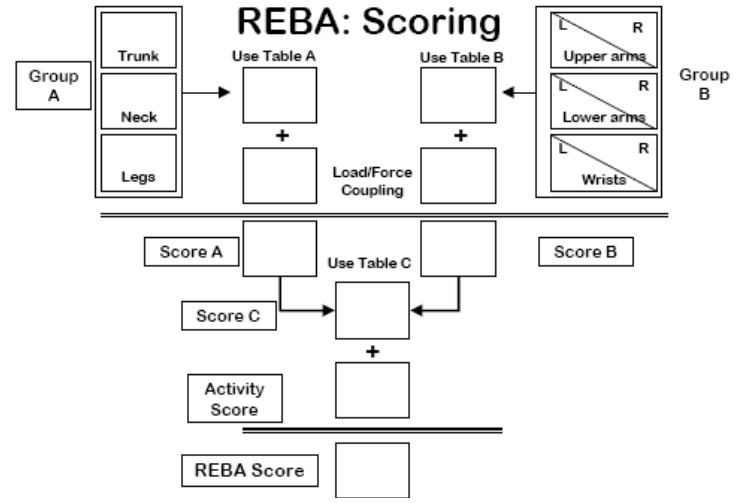

Fig. 2 REBA Score system

trolley ( 3 subtasks). All theses tasks are conducted inside a space of $5,25 \mathrm{~m} \times 5,25 \mathrm{~m}$, in which shelves are placed to store $10 \mathrm{Kg}$ vaccine packs, and pallets in the floor to store isothermal boxes weighting $24 \mathrm{Kg}$.

\subsection{Rapid Entire Body Assessment (REBA)}

REBA was originally created as a tool for evaluating posture in health care sector. In principle this postural analysis system is supposed to be sensitive to musculoskeletal risks in a variety of tasks. REBA incorporated dynamic and static postural loading factors, human -load interface (coupling), and a new concept of a gravity-assisted upper limb position [5]. REBA gives score divided by body group; score A is established by Neck, Trunk and Leg Analysis, score $\mathrm{B}$ is established by Arm and Wrist Analysis, score C is given by Score A and Score B and finally the final score is created with Score $\mathrm{C}$ and an adjustment to this one (see Figure 2). Critical postures associated with 8 tasks were evaluated with REBA.

\subsection{The revised NIOSH lifting equation}

The revised NIOSH lifting equation (RNLE) consists of two basic indicators: the recommended weight limit (RWL) and the lifting index (LI). The RWL is the main indicator of the revised NIOSH lifting equation. The RWL is defined for a specific set of task conditions as the weight of the load that nearly all healthy workers could perform over a substantial period of time (e.g. up to 8 hours) without an increased risk of developing lifting-related low back pain (LBP). The concept behind the revised NIOSH lifting equation is to start with a recommended weight that is considered safe for an 'ideal' lift (i.e. load constant equal to $23 \mathrm{~kg}$ or $51 \mathrm{lbs}$ ) and then reduces the weight as the task becomes more stressful. This is achieved throughout the multiplication of five quantified factors to the recommended weight considered as safe that is a multiplicative model with constant weight and discounting multipliers [11].

\section{Findings}

Results from the application of a questionnaire show the prevalence of musculoskeletal symptoms among all of workers. The main affected body re-

Table 1

Results of evaluation with NIOSH equation

\begin{tabular}{|c|c|c|c|c|c|c|c|c|}
\hline & HM & VM & DM & $\mathrm{AM}$ & FM & $\mathrm{CM}$ & RWL & LI \\
\hline \multicolumn{9}{|c|}{$\begin{array}{l}\text { Lifting } 10 \mathrm{~kg} \text { packs from trolley } \\
\text { to shelve }\end{array}$} \\
\hline $1^{\text {th }}$ Level & 1 & 0.84 & 1 & 0.90 & 0.45 & 0.95 & 7.4 & 1.35 \\
\hline $3^{\text {th }}$ Level & 1 & 0.84 & 0.86 & 0.90 & 0.45 & 0.95 & 6.4 & 1.56 \\
\hline $4^{\text {th }}$ Level & 1 & 0.84 & 0.0 & 0.90 & 0.45 & 0.95 & $\mathbf{0}$ & - \\
\hline \multicolumn{9}{|c|}{$\begin{array}{l}\text { Lowering } 10 \mathrm{~kg} \text { packs from } \\
\text { shelves to isothermals boxes }\end{array}$} \\
\hline $1^{\text {th }}$ Level & 1 & 0.83 & 1 & 1 & 0.45 & 0.95 & 7.7 & 1.29 \\
\hline $2^{\text {nd }}$ Level & 1 & 0.99 & 0.90 & 1 & 0.45 & 0.95 & 8.7 & 1.14 \\
\hline $3^{\text {th }}$ Level & 1 & 084 & 0.86 & 1 & 0.45 & 0.95 & 7 & 1.42 \\
\hline $4^{\text {th }}$ Level & 1 & 0 & 0 & 1 & 0.45 & 0.95 & 0 & - \\
\hline \multicolumn{9}{|c|}{$\begin{array}{l}\text { Lifting } 24 \mathrm{Kg} \text { isothermals boxes } \\
\text { from pa llet to troll ey }\end{array}$} \\
\hline
\end{tabular}


Table 2

Results from the application of REBA

\begin{tabular}{|c|c|c|c|c|c|}
\hline Postures & $\begin{array}{r}\text { Score } \\
\mathrm{A} \\
\end{array}$ & $\begin{array}{r}\text { Score } \\
\mathrm{B} \\
\end{array}$ & $\begin{array}{r}\text { Score } \\
\mathrm{C} \\
\end{array}$ & $\begin{array}{r}\text { Final } \\
\text { Score } \\
\end{array}$ & $\begin{array}{r}\text { Action } \\
\text { Level } \\
\end{array}$ \\
\hline 1 & 6 & 11 & 10 & 10 & High \\
\hline 2 & 6 & 5 & 8 & 8 & High \\
\hline 3 & 6 & 5 & 8 & 8 & High \\
\hline 4 & 7 & 7 & 9 & 9 & High \\
\hline 5 & 7 & 8 & 10 & 10 & High \\
\hline 6 & 8 & 6 & 10 & 10 & High \\
\hline 7 & 6 & 6 & 8 & 8 & High \\
\hline 8 & 3 & 6 & 5 & 5 & Med. \\
\hline
\end{tabular}

gions were: shoulders, neck and low back. Possible causes of these problems were identified during the study as: 1) unsuitable design of work elements, especially shelves and trolleys, 2) inadequate plant layout, which is responsible for limited space to organize shelves, pallets, corridors, and finally 3) the over-exertion imposed as a result of loads manipulated.

Evaluation was made following an event-based approach in which most frequent critical postures and tasks were selected. Eight of the eleven manual material handling tasks analyzed with NIOSH equation had a Lifting Index between 1.14 and 1.80 and two had a recommended weight limit of $0 \mathrm{~kg}$ indicating a need for job redesign in all cases (Table 1).Seven of the eight postures evaluated with REBA had a total score between 8 and 10, meaning a high risk, and only one was at a medium risk level (Table 2).

\subsection{The redesigns}

Some redesigns were aimed to improve the spatial geometry of lifting. In the case of shelves, maximum heights were decreased from $200 \mathrm{~cm}$ to $186 \mathrm{~cm}$ and minimum height increased from $17 \mathrm{~cm}$ to $64 \mathrm{~cm}$ by removing one level. The two-step stair allows increasing the reach to $62 \mathrm{~cm}$ when interacting with shelves. Only two stow levels were allowed for stocking isothermal boxes weighting $24 \mathrm{Kg}$ on pallets, instead of the three levels that existed before. Job rotation was introduced to decrease exposure time to less than $2 \mathrm{hr}$ a day. This was achieved by switching warehousing tasks with workplaces in the packing line. The pattern of using body parts is different between these two jobs. Thus it is supposed to allow rest. Finally the restructuration of plant layout made possible most of solution to be feasible due to their dependence to spaces availability. It should be noticed that the introduction of a two-workers lifting strategy implies an important change in work method. This is also the case of job rotation. After implementation a time for trying new solution should be allowed.

A new evaluation was conducted with changed parameters introduced as a result of proposed and implemented solutions. This evaluation shows a decreased score according to REBA, with five postures now at low risk level, two were at medium and only one remained in the category of high risk. According to NIOSH equation all tasks were at LI less than 0.7, meaning low risk.

\section{Discussion}

Plant layout can be an important source of discomfort associated with MSDs, especially when access becomes restricted and awkward postures are imposed. As described by Kourinka et al. the lack of space seems to be one of the main determinants associated with the lifting strategies adopted by workers[6]. Lack of space was associated in this study with the frequent use of $4^{\text {th }}$ and $1^{\text {st }}$ level shelves (200 $\mathrm{cm}$ and $17 \mathrm{~cm}$ height respectively), leading to manipulation of loads above the shoulder heights in the first case and to substantial flexion the trunk in the second case (Figure 2). These elements affected REBA final score (Table 1). Lack of space was also associated with improper access for the trolley, leading to more asymmetrical movements during the lifting of $10 \mathrm{Kg}$ packs of vaccines.

Lifting Index was mainly affected by the long duration of the job. Workers spend more than 6hrs a day conducting $\mathrm{MMH}$ tasks (peak production), with an average of 4 lifts per minute in the case of $10 \mathrm{Kg}$ packs of vaccines, and 2 lifts per minute in the case of $24 \mathrm{Kg}$ boxes. All of this impacted the frequency multiplier as it can be seen in Table 2. Surfaces heights for extracting and locating the load in shelves affected the vertical multiplier and the distance multiplier. In the case of DM, the distance traveled to lifting and lowering using $4^{\text {th }}$ level shelves made this MMH task unacceptable. Coupling multipliers were deemed as fair, although some authors prefer to just classify it in good or poor. The calculation of the LI for any of the eleven subtask were made assuming that each of them would be executed during a period corresponding to a set of subtasks (more than 2hr). This was made to avoid the use of the NIOSH composite lifting index (CLI); a fairly complex calculation for aggregating individual task assessments made with the 1991 NIOSH equation to a single in- 
$\operatorname{dex}[11]$. The objective of this study was not calculating an overall risk but identifying and evaluating the main determinants influencing the risk of MSDs associated with these MMH tasks.

The event-based approach for evaluation of MSDs risk was chosen instead of the time-based approach. This choice was made following criteria from Bao et $a l$., who found it easier to use and more suitable for practitioners[2]. The present study corroborates this idea. The use of some sample-based strategies would increase the complexity of the analysis.

It is important to notice that the original source of the anthropometric data, used in designs, was a study carried out by the Department of Anthropology at the University of Havana during the early's 70s. Although it is presumed that Cuban population has changed since then, no recent studies of the Cuban population regarding their anthropometric dimensions have been carried out. This fact was taken into consideration during the design phase in order to avoid any mismatch.

The thermal environment does not fit into the limits recommended for using the NIOSH equation (19$26 \mathrm{C}^{\circ}$ ), but the assumption adopted by authors is that the effect is negligible based on the fact that people adapt for preserving thermal comfort. Workers adjust by wearing coats and other personal protective equipment. People are not passive receptors of thermal discomfort[7].

\section{References}

[1] R. Avila, L. R. Prado, and E. L. Gónzalez, Dimensiones antropométricas de población latinoamericana: México, Cuba, Colombia y Chile. 2001, Guadalajara: Universidad de Guadalajara.

[2] S. Bao, N. Howard, P. Spielholz, and B. Silverstein, Two posture analysis approaches and their application in a modified Rapid Upper Limb Assessment evaluation, Ergonomics 50 (2007), 2118 - 2136

[3] D. Colombini, E. Occhipinti, N. Delleman, N. Fallentin, A. Kilbom, and A. Grieco, Exposure assessment of upper limb repetitive movements: a consensus document developed by the Technical Committee on Musculoskeletal Disorders of International Ergonomics Association (IEA) endorsed by International Commission on Occupational Health (ICOH). G Ital Med Lav Ergon Apr-Jun; 23 (2001), 129-42.

[4] S. Dagenais, J. Caro, and S. Haldeman, A systematic review of low back pain cost of illness studies in the United States and internationally, The Spine Journal 8 (2008), 8-20.

[5] S. Hignett and L. McAtamney, Rapid Entire Body Assessment (REBA), Applied Ergonomics 31 (2000), 201205.

[6] I. Kuorinka, M. Lortie, and M. Gautreau, Manual handling in warehouses: the illusion of correct working postures, Ergonomics 37 (1994), 655 - 661.

[7] K. C. Parsons, Ergonomics assessment of thermal environments, in Evaluation of human work, J.R. Wilson and E.N. Corlett, Editors. 2005, Taylor \& Francis: Boca Raton, Flor.

[8] Y. Torres, Y. Rodriguez, and S. Viña. Ergonomics intervention using movement analysis system and $3 D$ modeling techniques: a case from industrially developing country (IDC). in Seventh International Conference on Prevention of Work-Related Musculoskeletal Disorders, PREMUS. 2010. Angers (France).

[9] Y. Torres, Y. Rodríguez, and S. Viña, Preventing workrelated musculoskeletal disorders in $\mathrm{Cuba}$, an industrially developing country, Work: A Journal of Prevention, Assessment and Rehabilitation 38 (2011), 301-306.

[10] S. Viña, A. G. Rodríguez, S. Delgado, and A. Serradet. Diagnosis and design of workplaces at ARCA factory. in Fourth International Cyberspace Conference on Ergonomics, CybErg 2005. 2005. Johannesburg: International Ergonomics Association Press.

[11] T. R. Waters, V. Putz-Anderson, A. Garg, and L. J. Fine, Revised NIOSH equation for the design and evaluation of manual lifting tasks, Ergonomics 36 (1993), 749 - 776. 